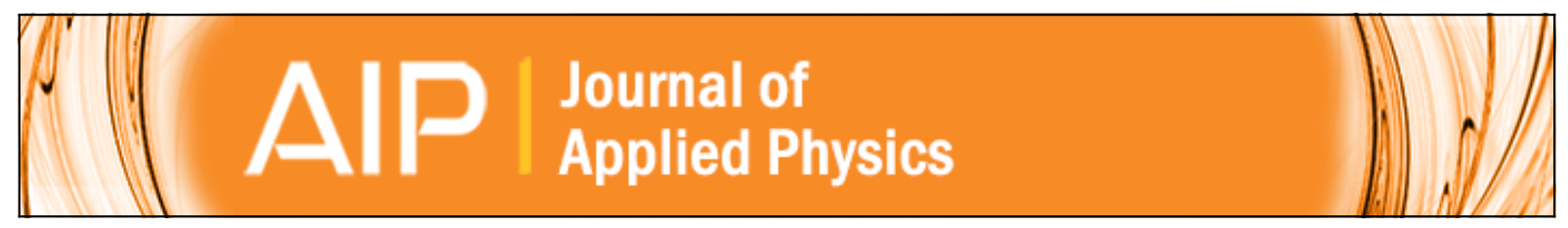

\title{
Dispersion of refractive properties of solvents: Chloroform, toluene, benzene, and carbon disulfide in ultraviolet, visible, and near-infrared
}

Anna Samoc

Citation: Journal of Applied Physics 94, 6167 (2003); doi: 10.1063/1.1615294

View online: http://dx.doi.org/10.1063/1.1615294

View Table of Contents: http://scitation.aip.org/content/aip/journal/jap/94/9?ver=pdfcov

Published by the AIP Publishing

\section{Articles you may be interested in}

Dispersion properties and low infrared optical losses in epitaxial AIN on sapphire substrate in the visible and infrared range

J. Appl. Phys. 115, 163515 (2014); 10.1063/1.4873236

Measurement of the refractive index dispersion of As2Se3 bulk glass and thin films prior to and after laser irradiation and annealing using prism coupling in the near- and mid-infrared spectral range

Rev. Sci. Instrum. 82, 053103 (2011); 10.1063/1.3587616

Negative refraction with high transmission at visible and near-infrared wavelengths

Appl. Phys. Lett. 92, 241108 (2008); 10.1063/1.2938413

Refractive Index and Dispersion of Fluorides and Oxides

J. Phys. Chem. Ref. Data 31, 931 (2002); 10.1063/1.1497384

Anomalous dispersion of dye solutions observed in a prismatic cuvette

Am. J. Phys. 66, 791 (1998); 10.1119/1.18958

\section{PIDEN}

Contact Hiden Analytical for further details: W www.HidenAnalytical.com E info@hiden.co.uk CLICK TO VIEW our product catalogue

\section{Instruments for Advanced Science}

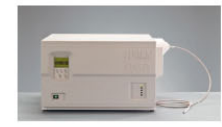

Gas Analysis

dynamic measurement of reaction gas streams catalysis and thermal analysis

molecular beam studies

fermentation, environmental and ecological studies

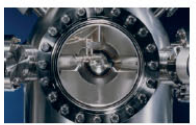

Surface Science

UHVTPD

SIMS

end point detection in ion beam etch elemental imaging - surface mapping

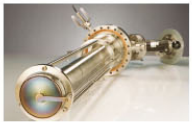

Plasma Diagnostics - plasma source characterization etch and deposition process reaction kinetic studies analysis of neutral and radical species

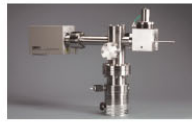

Vacuum Analysis - partial pressure measurement and contro of process gases reactive sputter process control vacuum diagnostics vacuum coating process monitoring 


\title{
Dispersion of refractive properties of solvents: Chloroform, toluene, benzene, and carbon disulfide in ultraviolet, visible, and near-infrared
}

\author{
Anna Samoc ${ }^{\text {a) }}$ \\ Laser Physics Centre, Research School of Physical Sciences and Engineering, Australian National \\ University, Canberra ACT 0200, Australia
}

(Received 25 February 2003; accepted 10 August 2003)

\begin{abstract}
Refractive index dispersion formulas have been derived for chloroform, toluene, benzene, and carbon disulfide from a broad range of the experimental refractive index data at $20^{\circ} \mathrm{C}$. The data were examined with the linear least-squares method. The dispersion equations allow one to calculate the values of refractive index required for analysis of nonlinear optical measurements in the UV, visible, and near-IR wavelength range $(0.3-2.5 \mu \mathrm{m})$ in these liquids and solutions. The indices were compared to those estimated from quantum chemical calculations. A survey of the experimental data revealed that the measurement results published recently [Opt. Mater. 20, 81 (2002); Rev. Sci. Instrum. 65, 2056 (1994); 66, 38 (1995); 69, 1243 (1998)] were significantly different from other data reported in the literature. (C) 2003 American Institute of Physics. [DOI: 10.1063/1.1615294]
\end{abstract}

\section{INTRODUCTION}

A wealth of experimental values of refractive index at $20{ }^{\circ} \mathrm{C}\left(n^{20}\right)$ of four important liquids: chloroform $\left(\mathrm{CHCl}_{3}\right)$, toluene $\left(\mathrm{C}_{6} \mathrm{H}_{5} \mathrm{CH}_{3}\right)$, benzene $\left(\mathrm{C}_{6} \mathrm{H}_{6}\right)$, and carbon disulfide $\left(\mathrm{CS}_{2}\right)$ in a broad wavelength range (about $0.3-2.5 \mu \mathrm{m}$ ) are accessible. ${ }^{1-13}$ This critical review of the values of linear refractive indices of the above liquids has been motivated by the fact that they are often used in the studies of nonlinear optical (NLO) effects in the near-infrared region (0.7-2.5 $\mu \mathrm{m})$. Many NLO experiments are carried at around $800 \mathrm{~nm}$ using femtosecond pulses from a Ti:sapphire solid state laser, however, the availability of optical parametric amplifiers (OPA) operating at longer wavelengths allows one to measure nonlinear responses from solids and solutions in the telecommunication wavelength range, $1.2-1.6 \mu \mathrm{m}$. The linear refractive indices are needed for determination of the third-order nonlinear optical properties (nonlinear refractive index, $n_{2}$, the third-order susceptibility, $\chi^{(3)}$ ) of solvents and solutes in solutions of organic materials. ${ }^{14-22}$ The NLO measurements can be performed on films of neat solid substances using, for example, degenerate four-wave mixing (DFWM) and Z-scan techniques with picosecond or femtosecond pulses, however, the procedure of measurements of solutions is quite convenient provided sufficient solubility of a compound is present. Refractive indices of a solvent, a solute, and of solutions are required to calculate the local field factor (the Lorentz factor, which relates local and external fields) in the derivation of the molecular nonlinearity, the second hyperpolarizability, $\gamma$, of molecules from the $\chi^{(3)}$ measurements. Also, an interest in the development of laser light sources and an increasing number of optoelectronic applications creates a need for the knowledge of the fundamental optical properties of materials in the telecommunication wavelength range. Solvents play an important role in the design of dye lasers; a cross section for stimulated emission

${ }^{a)}$ Electronic mail: anna.samoc@anu.edu.au depends on the refractive index of the active medium (the refractive index of a dilute solution is determined mainly by the index of the solvent).

The objective of the present work is to evaluate refractive indices of the solvents at longer wavelengths. They could be found either from measurements or from the interpolation of the experimental data provided a proper dispersion equation was available. In this article precise constants for the Cauchy's dispersion equations of linear refractive indices at $20^{\circ} \mathrm{C}$ are derived from available literature data for benzene, carbon disulfide, chloroform, and toluene in the UV-visible-near-infrared range.

A severe discrepancy exists between results of interferometric measurements recently reported in Refs. 1-4 and the refractive index values already published in the literature on the same materials. A paper ${ }^{1}$ entitled "Study of refractive properties of laser dye solvents: toluene, carbon disulfide, chloroform, and benzene" gave confusing values of refractive indices measured at two laser wavelengths, namely $\lambda$ $=514.5$ and $\lambda=632.8 \mathrm{~nm}$. These indices were partially reported in a series of papers, ${ }^{2-4}$ where they were used in the derivation of the constants of optical dispersion $(d n / d \lambda)$ at $600 \mathrm{~nm}$, optical permittivity $\left(\varepsilon=n^{2}\right)$, the dielectric dispersion $(d \varepsilon / d \lambda)$, and molecular constants: polarizability, molar refraction, molecular radius, etc. The wavelength dependence of the refractive index was described by a two parameter Cauchy's dispersion equation in the range $400-800 \mathrm{~nm} .{ }^{1}$

The refractive index data and the temperature gradient $(d n / d T)$ published in Refs. 1-4 were measured with the Mach-Zehnder laser interferometer developed in an earlier work, ${ }^{2}$ where the accuracy of $1 \times 10^{-5}$ was reported. A parallel plate sample cell was inserted in the one arm of the interferometer and rotated against the incident laser beam. Refractive index and thickness were determined from the relationship between a number of fringes shifted and the rotation angle of the sample. ${ }^{2,3}$ Measurements of optical constants in the liquids at $514.5 \mathrm{~nm}$ were described in Ref. 4. All these papers underlined an advantage of using an interfero- 
TABLE I. Experimental values of linear refractive index of liquid chloroform at $20^{\circ} \mathrm{C}$.

\begin{tabular}{|c|c|c|c|c|c|c|c|}
\hline$\lambda(\mathrm{nm})$ & $n^{20}$ & $\lambda(\mathrm{nm})$ & $n^{20}$ & $\lambda(\mathrm{nm})$ & $n^{20}$ & $\lambda(\mathrm{nm})$ & $n^{20}$ \\
\hline \multicolumn{2}{|c|}{ Data from Ref. 1} & \multicolumn{2}{|c|}{ Data from Ref. 6} & \multicolumn{2}{|c|}{ Data from Ref. $7^{b}$} & \multicolumn{2}{|c|}{ Data from Ref. $7^{b}$} \\
\hline 514.5 & 1.456661 & 434.0 & 1.4582 & 265.5 & 1.5051 & 589.3 & 1.4455 \\
\hline 632.8 & 1.441415 & 434.0 & 1.4570 & 289.4 & 1.4911 & 589.3 & 1.4454 \\
\hline Data from & Ref. $5^{a}$ & 486.1 & 1.4529 & 313.1 & 1.4806 & 656.28 & 1.4430 \\
\hline 396.8 & 1.463 & 486.1 & 1.4523 & 365.0 & 1.4661 & \multicolumn{2}{|c|}{ Data from Ref. 11} \\
\hline 434.1 & 1.458 & 589.3 & 1.4467 & 435.8 & 1.4546 & 2130 & 1.4329 \\
\hline 486.1 & 1.4530 & 589.3 & 1.4461 & 589.3 & 1.4467 & 2480 & 1.4317 \\
\hline 589.3 & 1.4467 & 656.3 & 1.4440 & 589.3 & 1.4459 & & \\
\hline 656.3 & 1.4443 & 656.3 & 1.4435 & 589.3 & 1.4456 & & \\
\hline
\end{tabular}

${ }^{a}$ The data for chloroform in the source (Ref. 5) were obtained from Ref. 28

${ }^{\mathrm{b}}$ The data in the source (Ref. 7) were listed after Refs. 29-32.

metric technique over other techniques for measuring refractive indices of liquids. It is known that the accuracy of interferometric measurements can be as high as to six decimal places. Such accuracy cannot be achieved with other optical methods, like the minimum angle of deviation or the Abbe refractometer, based on the effect of total reflection, which gives refractive index within the accuracy not better than $0.0001 .^{23}$ However, as shown below, the values of refractive index calculated at the wavelength $400-800 \mathrm{~nm}$ using dispersion constants derived in Ref. 1 are in disagreement with other literature data except for those for liquid benzene.

\section{EXPERIMENTAL DATA AND NUMERICAL DISPERSION RESULTS}

This examination of the dependence of the refractive index $n^{20}$ on wavelength in four neat liquids was based on the experimental values published in the reference sources ${ }^{5-10}$ and in original papers. ${ }^{11-13}$ Some data were obtained from the handbooks and sources, which were rather not easily accessible but were elegantly summarized by Nikogosyan. ${ }^{7}$ The index data were usually given for the Fraunhofer lines: C $(656.3 \mathrm{~nm}), \mathrm{D}(589.3 \mathrm{~nm}), \mathrm{F}(486.1 \mathrm{~nm}), \mathrm{G}^{\prime}(434.1 \mathrm{~nm})$, and other spectral lines of the hydrogen discharge or mercury arc. Not many data were available for common laser radiation sources.

Tables I-IV contain information on the available refrac- tive indices of four liquids in the ultraviolet, visible, and near-infrared region. Table I shows the data for chloroform in the wavelength range from 265.5 to $2480 \mathrm{~nm}$, Table II for toluene (404.66-830 nm), Table III for benzene (276.3$2190 \mathrm{~nm}$ ), and Table IV for carbon disulfide (340.4-2430 $\mathrm{nm})$.

The dependence of refractive indices on the wavelength $\lambda$ was approximated using the linear least-squares method for a function described with a formula $y=m_{1} x_{1}+m_{2} x_{2}$ $+m_{3} x_{3}+\cdots+b$. The dependent $y$ value was taken as a function of a range of multiple independent $x_{i}$ variables $\left(x_{i}\right.$ $=\lambda^{ \pm 2 i}$, where $\lambda$ is the wavelength, and $i$ is an integer), $b$ was a constant. The regression allowed us to calculate the $m_{i}$ coefficient (we use symbols $A_{i}, B_{i}, C_{i}$ later on). Additional regression statistics were applied to determine the standard error values for the $m_{i}$ coefficients, the standard error for the constant $b$, the coefficient of determination $r^{2}$, and the standard error $\sigma$ for the dependent $y$.

The refractive index spectrum can be described with various dispersion equations, ${ }^{6,24}$ among them the Sellmeier, and the Cauchy equations are the most useful. Equation (1) represents the Sellmeier's formula:

$$
n^{2}=1+\sum_{j} \frac{s_{j} \lambda^{2}}{\lambda^{2}-\lambda_{0 j}^{2}},
$$

where $\lambda_{0 j}$ is the wavelength of a corresponding characteris-

TABLE II. Experimental values of linear refractive index of liquid toluene at $20^{\circ} \mathrm{C}$.

\begin{tabular}{|c|c|c|c|c|c|c|c|}
\hline$\lambda(\mathrm{nm})$ & $n^{20}$ & $\lambda(\mathrm{nm})$ & $n^{20}$ & $\lambda(\mathrm{nm})$ & $n^{20}$ & $\lambda(\mathrm{nm})$ & $n^{20}$ \\
\hline \multicolumn{2}{|c|}{ Data from Ref. 1} & \multicolumn{2}{|c|}{ Data from Ref. $7^{\mathrm{b}}$} & \multicolumn{2}{|c|}{ Data from Ref. $7^{\mathrm{b}}$} & \multicolumn{2}{|c|}{ Data from Ref. $9^{c}$} \\
\hline 514.5 & 1.498921 & 404.66 & 1.526120 & 632.8 & 1.493680 & 435.6 & 1.51800 \\
\hline 632.8 & 1.495612 & 435.84 & 1.517830 & 643.85 & 1.493005 & 486.1 & 1.50847 \\
\hline \multicolumn{2}{|c|}{ Data from Ref. $5^{\mathrm{a}}$} & 479.99 & 1.509285 & 656.28 & 1.49243 & 501.6 & 1.50620 \\
\hline 434.1 & 1.5170 & 486.13 & 1.508315 & 656.28 & 1.492285 & 546.1 & 1.50086 \\
\hline 486.1 & 1.5070 & 486.13 & 1.50847 & 706.52 & 1.489795 & 589.3 & 1.49693 \\
\hline 589.3 & 1.4955 & 546.07 & 1.500715 & \multicolumn{2}{|c|}{ Data from Ref. 12} & 656.3 & 1.49243 \\
\hline 656.3 & 1.4911 & 587.56 & 1.496920 & 476.5 & 1.51008 & 667.8 & 1.49180 \\
\hline \multicolumn{2}{|c|}{ Data from Ref. 6} & 589.00 & 1.496800 & 488.0 & 1.50826 & \multicolumn{2}{|c|}{ Data from Ref. 13} \\
\hline 434.0 & 1.5174 & 589.3 & 1.49693 & 496.5 & 1.50701 & 830 & 1.4855 \\
\hline 486.1 & 1.5082 & 589.3 & 1.4969 & 514.5 & 1.50456 & & \\
\hline 589.3 & 1.4970 & 589.3 & 1.49691 & 632.8 & 1.49390 & & \\
\hline 656.3 & 1.4912 & 589.59 & 1.496755 & & & & \\
\hline
\end{tabular}

${ }^{\mathrm{a}}$ The data for toluene in the source (Ref. 5) were obtained from Ref. 28.

${ }^{\mathrm{b}}$ The source (Ref. 7) contains results from Refs. 33-37.

${ }^{\mathrm{c}}$ The source (Ref. 9) contains results from Ref. 38. 
TABLE III. Experimental values of linear refractive index of liquid benzene at $20^{\circ} \mathrm{C}$.

\begin{tabular}{|c|c|c|c|c|c|c|c|}
\hline$\lambda(\mathrm{nm})$ & $n^{20}$ & $\lambda(\mathrm{nm})$ & $n^{20}$ & $\lambda(\mathrm{nm})$ & $n^{20}$ & $\lambda(\mathrm{nm})$ & $n^{20}$ \\
\hline \multicolumn{2}{|c|}{ Data from Ref. 1} & \multicolumn{2}{|c|}{ Data from Ref. $7^{b}$} & \multicolumn{2}{|c|}{ Data from Ref. $7^{\mathrm{b}}$} & \multicolumn{2}{|c|}{ Data from Ref. $9^{c}$} \\
\hline 514.5 & 1.508948 & 308.1 & 1.587 & 589.3 & 1.50165 & 435.6 & 1.52302 \\
\hline 632.8 & 1.497866 & 313.3 & 1.582 & 589.3 & 1.50144 & 486.1 & 1.51313 \\
\hline \multicolumn{2}{|c|}{ Data from Ref. $5^{\mathrm{a}}$} & 326.1 & 1.570 & 589.3 & 1.50142 & 501.6 & 1.51077 \\
\hline 434.1 & 1.5236 & 340.4 & 1.560 & 589.3 & 1.50140 & 546.1 & 1.50521 \\
\hline 486.1 & 1.5132 & 346.6 & 1.556 & 589.3 & 1.50112 & 589.3 & 1.50112 \\
\hline 589.3 & 1.5012 & 361.0 & 1.548 & 589.3 & 1.5011 & 656.3 & 1.49643 \\
\hline 656.3 & 1.4965 & 404.66 & 1.5318 & 589.3 & 1.50100 & 667.8 & 1.49578 \\
\hline \multicolumn{2}{|c|}{ Data from Ref. 6} & 434.05 & 1.52361 & 643.85 & 1.49740 & \multicolumn{2}{|c|}{ Data from Ref. 12} \\
\hline 434.0 & 1.5236 & 434.05 & 1.52360 & 656.28 & 1.49663 & 476.5 & 1.51473 \\
\hline 486.1 & 1.5133 & 435.83 & 1.52319 & 656.28 & 1.49660 & 488.0 & 1.51284 \\
\hline 589.3 & 1.5014 & 467.82 & 1.516 & 656.28 & 1.49643 & 496.5 & 1.51152 \\
\hline 589.3 & 1.5007 & 479.99 & 1.51420 & 656.28 & 1.49635 & 514.5 & 1.50898 \\
\hline 589.3 & 1.5014 & 479.99 & 1.514 & 768.20 & 1.4911 & 632.8 & 1.49792 \\
\hline 656.3 & 1.4966 & 486.13 & 1.51327 & 800 & 1.489 & \multicolumn{2}{|c|}{ Data from Ref. 10} \\
\hline \multicolumn{2}{|c|}{ Data from Ref. $7^{b}$} & 486.13 & 1.51320 & 1000 & 1.485 & 2010 & 1.479 \\
\hline 276.3 & 1.625 & 486.13 & 1.51313 & 1500 & 1.480 & 2090 & 1.480 \\
\hline 283.7 & 1.619 & 486.13 & 1.51305 & 1850 & 1.478 & 2120 & 1.479 \\
\hline 288.1 & 1.612 & 508.6 & 1.509 & & & 2170 & 1.477 \\
\hline 298.1 & 1.598 & 546.07 & 1.50550 & & & 2190 & 1.477 \\
\hline
\end{tabular}

${ }^{\mathrm{a}}$ The data for benzene in the source (Ref. 5) were obtained from Ref. 28.

${ }^{\mathrm{b}}$ The data in the source (Ref. 7) were derived from Refs. 30-34, 36, 39-41.

${ }^{\mathrm{c}}$ The source (Ref. 9) contains results from Ref. 38.

tic resonance frequency (a position of an absorption band). The Sellmeier dispersion equation can be used to calculate refractive indices in the spectral region of the normal and anomalous dispersion. ${ }^{6}$

In the case of colorless transparent substances the variation of refractive index with wavelength, given by
Eq. (1), can be replaced with simpler formulas. In an absorption-free range, at a considerable distance to the absorption band, Eq. (1) expanded into power series with respect to $\lambda$ yields Cauchy's equations ${ }^{6,24}$ that can be represented by the formulas (2) and (3) (up to the fifth term of expansion):

TABLE IV. Experimental values of linear refractive index of liquid $\mathrm{CS}_{2}$ at $20^{\circ} \mathrm{C}$.

\begin{tabular}{|c|c|c|c|c|c|c|c|}
\hline$\lambda(\mathrm{nm})$ & $n^{20}$ & $\lambda(\mathrm{nm})$ & $n^{20}$ & $\lambda(\mathrm{nm})$ & $n^{20}$ & $\lambda(\mathrm{nm})$ & $n^{20}$ \\
\hline \multicolumn{2}{|c|}{ Data from Ref. 1} & \multicolumn{2}{|c|}{ Data from Ref. $7^{b}$} & \multicolumn{2}{|c|}{ Data from Ref. $8^{\mathrm{c}}$} & \multicolumn{2}{|c|}{ Data from Ref. $8^{c}$} \\
\hline 514.5 & 1.636019 & 560.8 & 1.6333 & 546.1 & 1.63608 & 435.9 & 1.67377 \\
\hline 632.8 & 1.623977 & 578 & 1.6298 & 587.6 & 1.62804 & 447.2 & 1.66805 \\
\hline \multicolumn{2}{|c|}{ Data from Ref. $5^{\mathrm{a}}$} & 587.56 & 1.62804 & 589.3 & 1.62774 & 471.3 & 1.65771 \\
\hline 434.1 & 1.6748 & 589.3 & 1.6278 & 643.85 & 1.61966 & 486.1 & 1.65230 \\
\hline 486.1 & 1.6523 & 589.3 & 1.62774 & 656.3 & 1.61820 & 501.6 & 1.64742 \\
\hline 589.3 & 1.6276 & 589.3 & 1.6277 & 768.2 & 1.60800 & 546.1 & 1.63610 \\
\hline 656.3 & 1.6182 & 589.3 & 1.6276 & 361.2 & 1.73806 & 579.1 & 1.62961 \\
\hline \multicolumn{2}{|c|}{ Data from Ref. 6} & 589.3 & 1.627 & 394.4 & 1.70180 & 587.6 & 1.62801 \\
\hline 434.0 & 1.6752 & 610.4 & 1.6243 & 441.6 & 1.67135 & 589.0 & 1.62776 \\
\hline 486.1 & 1.6527 & 643.85 & 1.61966 & 467.8 & 1.65923 & 656.3 & 1.61816 \\
\hline 656.3 & 1.6185 & 656.28 & 1.6182 & 480.0 & 1.65466 & 667.8 & 1.61686 \\
\hline \multicolumn{2}{|c|}{ Data from Ref. $7^{\mathrm{b}}$} & 670.8 & 1.6168 & 508.6 & 1.64541 & 397.0 & 1.69940 \\
\hline 404.66 & 1.6934 & 768.20 & 1.6080 & 533.9 & 1.63877 & 434.0 & 1.67480 \\
\hline 434.05 & 1.6750 & Data from & 7 and 11 & 589.3 & 1.62761 & 486.0 & 1.65230 \\
\hline 435.83 & 1.6742 & 2030 & 1.585 & 340.4 & 1.77580 & 589.0 & 1.62760 \\
\hline 460.2 & 1.6618 & 2200 & 1.584 & 344.4 & 1.76850 & 656.0 & 1.61820 \\
\hline 479.99 & 1.6544 & 2430 & 1.583 & 346.7 & 1.76440 & 589.0 & 1.62750 \\
\hline 486.13 & 1.65234 & \multicolumn{2}{|c|}{ Data from Ref. $8^{\mathrm{c}}$} & 361.2 & 1.73950 & 777.0 & 1.60720 \\
\hline 486.13 & 1.65225 & 589.0 & 1.62800 & 366.4 & 1.73250 & 873.0 & 1.60170 \\
\hline 497.2 & 1.6488 & 404.6 & 1.69340 & 388.9 & 1.70609 & 999.0 & 1.59680 \\
\hline 508.6 & 1.6455 & 434.0 & 1.67500 & 396.5 & 1.69960 & 1164 & 1.59280 \\
\hline 527 & 1.6405 & 435.8 & 1.67420 & 402.6 & 1.69478 & 1396 & 1.58910 \\
\hline 546.07 & 1.63608 & 480.0 & 1.65440 & 407.8 & 1.69105 & 1745 & 1.58560 \\
\hline 546.07 & 1.6360 & 486.1 & 1.65225 & 412.1 & 1.68799 & 1998 & 1.58400 \\
\hline
\end{tabular}

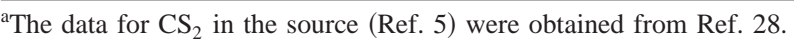

${ }^{\mathrm{b}}$ The source (Ref. 7) contains results from Refs. 29, 33, 34, 39, 42-44.

${ }^{\mathrm{c}}$ The source (Ref. 8) contains data from Refs. $45-50$. 
TABLE V. Constants of Cauchy's equations and calculated refractive indices of liquid chloroform at $20^{\circ} \mathrm{C}$.

\begin{tabular}{llll}
\hline \hline Parameter $^{\mathrm{a}}$ & \multicolumn{1}{c}{$y=n^{2}\left(\lambda^{-2}, \lambda^{-4}, \lambda^{-6}\right)^{\mathrm{a}}$} & \multicolumn{1}{c}{ Parameter $^{\mathrm{b}}$} & \multicolumn{1}{c}{$y=n\left(\lambda^{-2}, \lambda^{-4}, \lambda^{-6}\right)^{\mathrm{b}}$} \\
\hline$A_{0}$ & $2.048766 \pm 0.001728$ & $B_{0}$ & $1.431364 \pm 0.000595$ \\
$A_{1}\left(10^{3} \mathrm{~nm}^{2}\right)$ & $16.1937 \pm 1.0373$ & $B_{1}\left(10^{3} \mathrm{~nm}^{2}\right)$ & $5.63241 \pm 0.35709$ \\
$A_{2}\left(10^{8} \mathrm{~nm}^{4}\right)$ & $-5.9111 \pm 1.8380$ & $B_{2}\left(10^{8} \mathrm{~nm}^{4}\right)$ & $-2.0805 \pm 0.6327$ \\
$A_{3}\left(10^{13} \mathrm{~nm}^{6}\right)$ & $3.7358 \pm 0.8978$ & $B_{3}\left(10^{13} \mathrm{~nm}^{6}\right)$ & $1.2613 \pm 0.3091$ \\
$r^{2}$ & 0.99785 & $r^{2}$ & 0.99781 \\
$\sigma\left(10^{-4}\right)$ & 24.00 & $\sigma\left(10^{-4}\right)$ & 8.26 \\
Calculated values $n^{20}$ for $\mathrm{CHCl}_{3}:$ & & \\
$\lambda(\mathrm{nm})$ & $n_{\text {calc. from }}$ & $\lambda(\mathrm{nm})$ & $n_{\text {calc. }}$ from \\
& $y=n^{2}\left(\lambda^{-2}, \lambda^{-4}, \lambda^{-6}\right)^{\mathrm{a}}$ & & $y=n\left(\lambda^{-2}, \lambda^{-4}, \lambda^{-6}\right)^{\mathrm{b}}$ \\
514.5 & 1.45035 & 514.5 & 1.45035 \\
532 & 1.44922 & 532 & 1.44922 \\
589.3 & 1.44616 & 589.3 & 1.44616 \\
632.8 & 1.44433 & 632.8 & 1.44433 \\
800.0 & 1.43971 & 800.0 & 1.43970 \\
1064 & 1.43619 & 1064 & 1.43619 \\
1550 & 1.43367 & 1550 & 1.43367 \\
\hline \hline
\end{tabular}

${ }^{a}$ Equation (2).

${ }^{\mathrm{b}}$ Equation (3).

$$
n^{2}=A_{0}+\frac{A_{1}}{\lambda^{2}}+\frac{A_{2}}{\lambda^{4}}+\frac{A_{3}}{\lambda^{6}}+\frac{A_{4}}{\lambda^{8}},
$$

and

$$
n=B_{0}+\frac{B_{1}}{\lambda^{2}}+\frac{B_{2}}{\lambda^{4}}+\frac{B_{3}}{\lambda^{6}}+\frac{B_{4}}{\lambda^{8}} .
$$

The constants $A_{0}$, and $B_{0}$, i.e., the zero terms $(i=0)$ in the series $1 / \lambda^{2 i}$ in Eqs. (2) and (3), represent the refractive index $n_{\infty}^{2}$ and $n_{\infty}$ for infinite wavelength $(\lambda \rightarrow \infty)$, respectively.

An improvement in fitting of the refractive indices of liquids in the UV-visible-near-IR range is expected ${ }^{24,25}$ if the additional term in Eq. (4), due to the infrared vibrational absorption, ${ }^{25} C_{5} \lambda^{2}$, is added to the terms in $\lambda^{-2 i}$, which arise from the contribution of the ultraviolet electronic absorption:

$$
n=C_{0}+\frac{C_{1}}{\lambda^{2}}+\frac{C_{2}}{\lambda^{4}}+\frac{C_{3}}{\lambda^{6}}+\frac{C_{4}}{\lambda^{8}}+C_{5} \lambda^{2} .
$$

In order to obtain a satisfactory dispersion formula, it was necessary to consider all possible representations given by formulas (1)-(3) as well as those mentioned in Ref. 6. The regression statistics were used as a tool to choose the equations for the best fitting of refractive index experimental data. Initially the analysis was performed using a one term Sellmeier equation (1). The wavelength $\lambda_{0}$ was derived for each liquid, for example, $108 \mathrm{~nm}$ was obtained for chloroform, $138 \mathrm{~nm}$ for toluene, $146 \mathrm{~nm}$ for benzene, and $183 \mathrm{~nm}$ for $\mathrm{CS}_{2}$. A careful inspection of the graphs made of the one-term Sellmeier Eq. (1), represented in the linear form $\left(n^{2}-1\right)^{-1}=\left(s_{1}\right)^{-1}-\left(\lambda_{01} / \lambda\right)^{2}$, showed that the experimental points formed a curvature, and the value of the regression coefficient was not satisfactory $\left(r^{2}\right.$ was 0.99577 for chloroform, 0.99753 for toluene, 0.99792 for benzene, 0.99522 for $\mathrm{CS}_{2}$ ) indicating that more than one UV resonance should be taken into account in these considerations. A similar conclusion was drawn from the inspection of a modified Sellmeier equation, Eq. (20-10) in Ref. 23. There the relation $n^{2}=1+s\left[\left(1-\left(\lambda_{0} / \lambda\right)^{2}\right]^{-1}=1+s+s\left(\lambda_{0} / \lambda\right)^{2}\right.$ $+s\left(\lambda_{0} / \lambda\right)^{4}+\cdots$, has the form similar to Cauchy's equation, Eq. (2). The formula was derived ${ }^{23}$ for the case of a single absorption band and when a distance to the short wavelength side of the region, for which the dispersion is required, is considerably large, i.e., $\lambda^{2} \gg \lambda_{0}^{2}$ in Eq. (1). A single value of the constant $s$ [equal to $A_{0}$ in Eq. (2)] could satisfy this relation only if several values of $\lambda_{0}$ were taken into account proving that several resonances should be taken into consideration to describe the refractive index dispersion in any of these liquids. Therefore we analyzed the experimental data from Tables I-IV using the Cauchy equations (2)-(4).

Tables V-VIII contain values of the dispersion constants $A_{i}, B_{i}, C_{i}$, their standard errors, the coefficient of determination $r^{2}$, and the standard error $\sigma$ for the dependent $y$ fitting the experimental index data with $y=n^{2}$ and $y=n$ for each liquid. The choice of a number of terms in $\lambda^{ \pm 2 i}$ was dependent on the $r^{2}$ value (being closer to 1), and the values of the standard errors. The data from Refs. 1-4 were not included in these calculations. The lower parts of Tables V-VIII contain the values of refractive index calculated at several wavelengths of frequently used lasers. The standard errors are rather large due to the scatter of the experimental data obtained from many authors and measured with different techniques. The dispersion of optical permittivity $\left(\varepsilon=n^{2}\right)$ of studied liquids is represented with constants of Eq. (2). It can be noticed that the fitting coefficients of the Cauchy's Eq. (2) or Eq. (3) give identical values of calculated refractive indices.

Refractive properties of liquid chloroform were represented with 25 experimental values of $n^{20}$. The wavelength dependence was characterized with three $\lambda$-dependent terms as it is shown in Table V. Adding the term in $1 / \lambda^{8}$ slightly improved the $r^{2}$ value from 0.99785 to 0.99791 when $y$ $=n^{2}$, or from 0.99781 to 0.99788 when $y=n$, but increased the standard error for the constants $A_{0}$ and $B_{0}$ thus we decided to limit the number of terms to three. 
TABLE VI. Constants of Cauchy's equations and calculated refractive indices of liquid toluene at $20^{\circ} \mathrm{C}$.

\begin{tabular}{llll}
\hline \hline Parameter $^{\mathrm{a}}$ & \multicolumn{1}{c}{$y=n^{2}\left(\lambda^{-2}, \lambda^{-2}, \lambda^{-4}\right)^{\mathrm{a}}$} & \multicolumn{1}{c}{ Parameter $^{\mathrm{b}}$} & \multicolumn{1}{c}{$y=n\left(\lambda^{-2}, \lambda^{-4}\right)^{\mathrm{b}}$} \\
\hline$A_{0}$ & $2.175132 \pm 0.002395$ & $B_{0}$ & $1.474775 \pm 0.000797$ \\
$A_{1}\left(10^{3} \mathrm{~nm}^{2}\right)$ & $20.4682 \pm 1.3647$ & $B_{1}\left(10^{3} \mathrm{~nm}^{2}\right)$ & $6.99031 \pm 0.45379$ \\
$A_{2}\left(10^{8} \mathrm{~nm}^{4}\right)$ & $7.3100 \pm 1.8139$ & $B_{2}\left(10^{8} \mathrm{~nm}^{4}\right)$ & $2.1776 \pm 0.6032$ \\
$r^{2}$ & 0.99764 & $r^{2}$ & 0.99764 \\
$\sigma\left(10^{-4}\right)$ & 14.51 & $\sigma\left(10^{-4}\right)$ & 4.82 \\
Calculated values $n^{20}$ for $\mathrm{C}_{6} \mathrm{H}_{5} \mathrm{CH}_{3}:$ & & \\
$\lambda(\mathrm{nm})$ & $n_{\text {calc. from }}$ & $\lambda(\mathrm{nm})$ & $n_{\text {calc. from }}$ \\
& $y=n^{2}\left(\lambda^{-2}, \lambda^{-4}\right)^{\mathrm{a}}$ & & $y=n\left(\lambda^{-2}, \lambda^{-4}\right)^{\mathrm{b}}$ \\
514.5 & 1.50429 & 514.5 & 1.50429 \\
532 & 1.50219 & 532 & 1.50219 \\
589.3 & 1.49671 & 589.3 & 1.49671 \\
632.8 & 1.49359 & 632.8 & 1.49359 \\
800.0 & 1.48624 & 800.0 & 1.48623 \\
1064 & 1.48114 & 1064 & 1.48112 \\
\hline \hline
\end{tabular}

${ }^{a}$ Equation (2).

${ }^{\mathrm{b}}$ Equation (3).

A graphic representation of the experimental refractive indices of chloroform and these calculated from the fit with the three $\lambda$-dependent terms of Cauchy's Eq. (3) using parameters from Table $\mathrm{V}$ in the wavelength range $250-2500$ $\mathrm{nm}$ is shown as curve 1 in Fig. 1. This curve is compared to the dispersion curve 2 obtained for the range 400-800 nm from one $\lambda$-dependent term of the Cauchy equation of the type $n=A+\left(B / \lambda^{2}\right)$, taking values of the constants $A$ $=1.41167$, and $B=11909.0909 .{ }^{1}$ The graph shows significantly different dispersion curves and values of refractive indices measured in Ref. 1 at the same wavelength, and those obtained from interpolation using Eq. (2) or Eq. (3). The differences become larger at 400 and $800 \mathrm{~nm}$. Curve 1 in Fig. 1 shows a trend in the change of refractive index which cannot be experimentally verified due to a lack of data in the range $0.7-2 \mu \mathrm{m}$. The refractive index in the near-infrared region is almost constant. Here the tail of normal dispersion caused by the electronic absorption in UV overlaps with the high-energy tail of the anomalous dispersion caused by weaker vibrational absorption in the infrared. ${ }^{25}$ One may expect that the $\mathrm{C}-\mathrm{H}$ overtones might impose a structure on the dispersion curve in the near-infrared wavelength range. The experimental evidence ${ }^{25}$ did not show the influence of overtones on refractive indices beyond the accuracy of the measurements using the Abbe refractometer $\left(2 \times 10^{-4}\right)$ because absorption of the higher-order overtones in the near infrared is very weak. The steep dependence of refractive index on wavelength in chloroform, given in Ref. 1 and shown by curve 2 in Fig. 1, does not appear to be justified.

Liquid toluene was characterized with 37 values of refractive index. All of them were measured within a relatively narrow wavelength range from 405 to $830 \mathrm{~nm}$. The fitting parameters and the $r^{2}$ values in Table VI were obtained from Eqs. (2) and (3) based on two $\lambda$-dependent terms. Almost

TABLE VII. Constants of Cauchy's equations and calculated refractive indices of liquid benzene at $20^{\circ} \mathrm{C}$.

\begin{tabular}{llll}
\hline \hline Parameter ${ }^{\mathrm{a}, \mathrm{b}, \mathrm{c}}$ & $y=n^{2}\left(\lambda^{-2}, \lambda^{-4}, \lambda^{-6}, \lambda^{-8}\right)^{\mathrm{a}}$ & $y=n\left(\lambda^{-2}, \lambda^{-4}, \lambda^{-6}, \lambda^{-8}\right)^{\mathrm{b}}$ & $y=n\left(\lambda^{-2}, \lambda^{-4}, \lambda^{-6}, \lambda^{-8}, \lambda^{2}\right)^{\mathrm{c}}$ \\
\hline$A_{0}, B_{0}, C_{0}$ & $2.178271 \pm 0.000989$ & $1.475922 \pm 0.000315$ & $1.473644 \pm 0.001304$ \\
$A_{1}, B_{1}, C_{1}\left(10^{3} \mathrm{~nm}^{2}\right)$ & $28.7420 \pm 1.1374$ & $9.67157 \pm 0.36181$ & $11.26920 \pm 0.95679$ \\
$A_{2}, B_{2}, C_{2}\left(10^{8} \mathrm{~nm}^{4}\right)$ & $-15.5591 \pm 4.0503$ & $-5.2538 \pm 1.2884$ & $-9.2034 \pm 2.5347$ \\
$A_{3}, B_{3}, C_{3}\left(10^{13} \mathrm{~nm}^{6}\right)$ & $26.1346 \pm 5.0427$ & $8.5442 \pm 1.6041$ & $12.430 \pm 2.674$ \\
$A_{4}, B_{4}, C_{4}\left(10^{18} \mathrm{~nm}^{8}\right)$ & $-7.6948 \pm 2.0083$ & $-2.6163 \pm 0.6388$ & $-3.9224 \pm 0.9598$ \\
$C_{5}\left(10^{-10} \mathrm{~nm}^{-2}\right)$ & & & $4.8623 \pm 2.7035$ \\
$r^{2}$ & 0.999603 & 0.999616 & 0.999635 \\
$\sigma\left(10^{-4}\right)$ & 21.40 & 6.81 & 6.69 \\
Calculated values $n^{20}$ for $\mathrm{C}_{6} \mathrm{H}_{6}:$ & & & $n_{\text {calc }}$ \\
$\lambda(\mathrm{nm})$ & $n_{\text {calc }}$ from & $n_{\text {calc }}$ from \\
& $y=n^{2}\left(\lambda^{-2}, \lambda^{-4}, \lambda^{-6}, \lambda^{-8}\right)^{\mathrm{a}}$ & $1=n\left(\lambda^{-2}, \lambda^{-4}, \lambda^{-6}, \lambda^{-8}\right)^{\mathrm{b}}$ & \\
514.5 & 1.50903 & 1.50903 & 1.50911 \\
532.0 & 1.50689 & 1.50690 & 1.50698 \\
589.3 & 1.50128 & 1.50128 & 1.50133 \\
632.8 & 1.49804 & 1.49803 & 1.49802 \\
800.0 & 1.49008 & 1.49006 & 1.48977 \\
1064 & 1.48412 & 1.48411 & 1.48351 \\
1550 & 1.47986 & 1.47986 & 1.47935 \\
\hline \hline
\end{tabular}

${ }^{\mathrm{a} E q u a t i o n}(2)$.

${ }^{\mathrm{b}}$ Equation (3).

${ }^{\mathrm{c}}$ Equation (4). 
TABLE VIII. Constants of Cauchy's equations and calculated refractive indices of liquid $\mathrm{CS}_{2}$ at $20^{\circ} \mathrm{C}$.

\begin{tabular}{|c|c|c|c|}
\hline Parameter ${ }^{\mathrm{a}, \mathrm{b}, \mathrm{c}}$ & $y=n^{2}\left(\lambda^{-2}, \lambda^{-4}, \lambda^{-6}, \lambda^{-8}\right)^{\mathrm{a}}$ & $y=n\left(\lambda^{-2}, \lambda^{-4}, \lambda^{-6}, \lambda^{-8}\right)^{\mathrm{b}}$ & $y=n\left(\lambda^{-2}, \lambda^{-4}, \lambda^{-6}, \lambda^{-8}, \lambda^{2}\right)^{\mathrm{c}}$ \\
\hline$A_{0}, B_{0}, C_{0}$ & $2.499210 \pm 0.000608$ & $1.580826 \pm 0.000178$ & $1.582445 \pm 0.000585$ \\
\hline$A_{1}, B_{1}, C_{1}\left(10^{3} \mathrm{~nm}^{2}\right)$ & $47.4871 \pm 1.0077$ & $15.2389 \pm 0.2949$ & $13.7372 \pm 0.5910$ \\
\hline$A_{2}, B_{2}, C_{2}\left(10^{8} \mathrm{~nm}^{4}\right)$ & $22.644 \pm 4.987$ & $4.8578 \pm 1.4596$ & $10.0243 \pm 2.2686$ \\
\hline$A_{3}, B_{3}, C_{3}\left(10^{13} \mathrm{~nm}^{6}\right)$ & $-38.030 \pm 8.947$ & $-8.2863 \pm 2.6186$ & $-15.6572 \pm 3.5766$ \\
\hline$A_{4}, B_{4}, C_{4}\left(10^{19} \mathrm{~nm}^{8}\right)$ & $5.8058 \pm 0.5225$ & $1.4619 \pm 0.1529$ & $1.8294 \pm 0.1940$ \\
\hline$C_{5}\left(10^{-10} \mathrm{~nm}^{-2}\right)$ & & & $-3.2117 \pm 1.1099$ \\
\hline$r^{2}$ & 0.999939 & 0.999942 & 0.999947 \\
\hline$\sigma\left(10^{-4}\right)$ & 10.99 & 3.22 & 3.08 \\
\hline \multicolumn{4}{|c|}{ Calculated values $n^{20}$ for $\mathrm{CS}_{2}$ : } \\
\hline$\lambda(\mathrm{nm})$ & $\begin{array}{l}n_{\text {calc }} \text { from } \\
y=n^{2}\left(\lambda^{-2}, \lambda^{-4}, \lambda^{-6}, \lambda^{-8}\right)^{\mathrm{a}}\end{array}$ & $\begin{array}{l}n_{\text {calc }} \text { from } \\
y=n\left(\lambda^{-2}, \lambda^{-4}, \lambda^{-6}, \lambda^{-8}\right)^{\mathrm{b}}\end{array}$ & $\begin{array}{l}n_{\text {calc }} \text { from } \\
y=n\left(\lambda^{-2}, \lambda^{-4}, \lambda^{-6}, \lambda^{-8}, \lambda^{2}\right)^{\mathrm{c}}\end{array}$ \\
\hline 514.5 & 1.64385 & 1.64384 & 1.64385 \\
\hline 532 & 1.63937 & 1.63936 & 1.63935 \\
\hline 589.3 & 1.62777 & 1.62776 & 1.62772 \\
\hline 632.8 & 1.62119 & 1.62119 & 1.62115 \\
\hline 800.0 & 1.60556 & 1.60559 & 1.60566 \\
\hline 1064 & 1.59458 & 1.59462 & 1.59490 \\
\hline 1550 & 1.58724 & 1.58725 & 1.58755 \\
\hline
\end{tabular}

${ }^{\mathrm{a}}$ Equation (2).

${ }^{\mathrm{b}}$ Equation (3).

${ }^{\mathrm{c}}$ Equation (4).

identical $r^{2}$ values were found using the equations based on three $\lambda$-dependent terms but the standard error for the constant $A_{0}$ was higher. The refractive indices, calculated from Eqs. (2) and (3) (see the lower part of Table VI) were slightly different if they were calculated with the formulas extrapolated to longer wavelengths. Figure 2 shows the experimental data of refractive indices, $n^{20}$ of toluene, and the fit with Cauchy's Eq. (3) using parameters of two $\lambda$ terms from Table VI which are represented with curve 1 . Curve 2 represents the fit, $n=A+\left(B / \lambda^{2}\right)$, using the values $A=1.48916$ and $B$ $=2584.4419 .{ }^{1}$ It can be noticed that the experimental index values measured in Ref. 1 and these predicted with the calculated curve 2 have a weaker dispersion than that obtained from the fitting of the experimental data from many other references. The experimental $n$ values from Ref. 1 were too different to be included in the derivation of the dispersion constants for toluene.

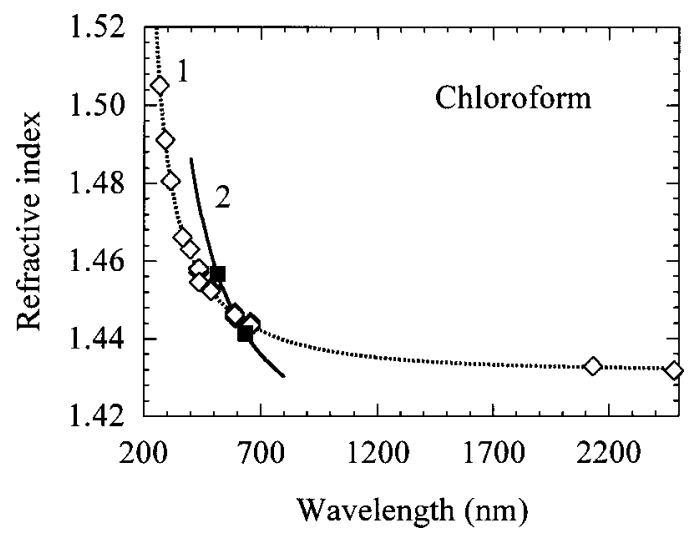

FIG. 1. Dispersion of refractive index of liquid chloroform at $20^{\circ} \mathrm{C}$. Diamonds are the experimental data from Table I; closed squares are the data measured in Ref. 1. Curve 1 (dotted line) was calculated using $n$ $=1.431364+5632.41 / \lambda^{2}-2.0805 \times 10^{8} / \lambda^{4}+1.2613 \times 10^{13} / \lambda^{6} ;$ curve 2 (solid line) is the dispersion curve from Ref. 1.
Refractive properties of liquid benzene were described with a large amount of refractive index data points (66). The dispersion coefficients, given in Table VII, were determined with the four $\lambda$-dependent terms of Eqs. (2) and (3), and using five $\lambda$-dependent terms in Eq. (4). The experimental data were more consistent than these for chloroform and toluene, the $r^{2}$ values being closer to 1 . The presence of the fifth $\lambda$-dependent term in Eq. (4) increased the standard error for the constant $C_{0}$. Figure 3 shows the fit of the experimental refractive indices, $n^{20}$, of liquid benzene with Cauchy's Eq. (3) using parameters of four $\lambda$ terms from Table VII in the wavelength range 240-2200 nm (curve 1). Curve 2 represents the fit, $n=A+\left(B / \lambda^{2}\right)$, using the values $A$ $=1.47625$ and $B=8654.7573$ calculated in Ref. 1 . The index data from Ref. 1 agreed well with other experimental data, curves 1 and 2 in Fig. 3 overlap well for benzene within the wavelength range $400-800 \mathrm{~nm}$.

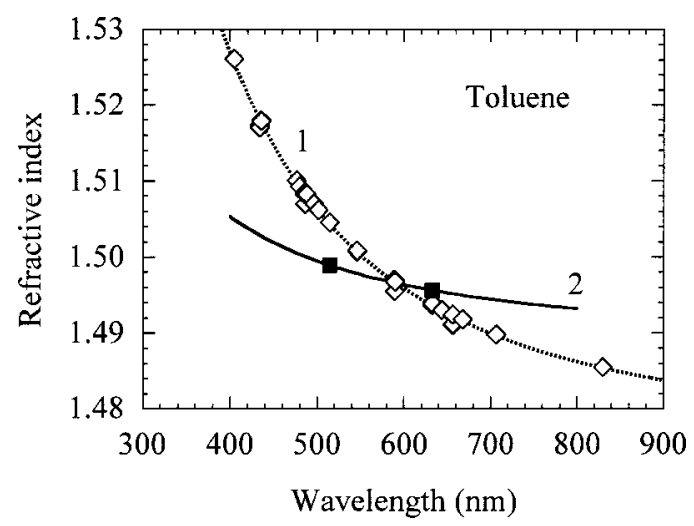

FIG. 2. Dispersion of refractive index of liquid toluene at $20^{\circ} \mathrm{C}$. Diamonds are the experimental refractive index data from Table II; closed squares are the data measured in Ref. 1. Curve 1 (dotted line) was calculated using $n$ $=1.474775+6990.31 / \lambda^{2}+2.1776 \times 10^{8} / \lambda^{4}$; curve 2 (solid line) is the dispersion curve shown in Ref. 1. 


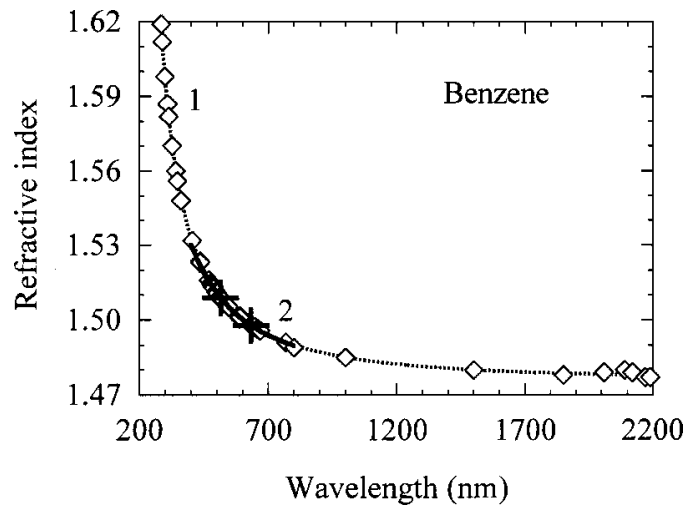

FIG. 3. Dispersion of refractive index of liquid benzene at $20^{\circ} \mathrm{C}$. Diamonds are the experimental index data from Table III; crosses are the data measured in Ref. 1. Curve 1 (dotted line) was calculated using $n=1.475922+9671.57 / \lambda^{2}-5.2538 \times 10^{8} / \lambda^{4}+8.5442 \times 10^{13} / \lambda^{6}-2.6163$ $\times 10^{18} / \lambda^{8}$; curve 2 (solid line) is the dispersion curve from Ref. 1 .

Among other standard liquids carbon disulfide has the biggest representation of the experimental values of refractive indices (88). The dispersion of $n^{20}$ was fitted with Eqs. (2)-(4) in the wavelength range $340.4-2430 \mathrm{~nm}$. Table VIII shows the $r^{2}$ values close to 0.99994 indicating consistency in the experimental data. The standard deviation of the experimental $n$ value was about $3 \times 10^{-4}$, which was lower than in benzene proving better accuracy. Figure 4 shows the fit of the experimental refractive indices, $n^{20}$, of liquid $\mathrm{CS}_{2}$ with Cauchy's Eq. (3) using four $\lambda$ terms (the curve 1). The fitting parameters were taken from Table VIII. The dispersion of refractive index of $\mathrm{CS}_{2}$ calculated in this work is different from the relation $n=A+\left(B / \lambda^{2}\right)$ represented by the curve 2 calculated using $A=1.60049$ and $B=9404.9747$ from Ref. 1. The dispersion of the linear refractive index obtained here (curve 1) is steeper than the dependence (curve 2) predicted in Ref. 1.

To comment on the alternate way of obtaining dispersion of the refractive index by semiempirical quantum chemical calculations, the values of refractive index and dispersion were also estimated using the Molecular Orbital Package,

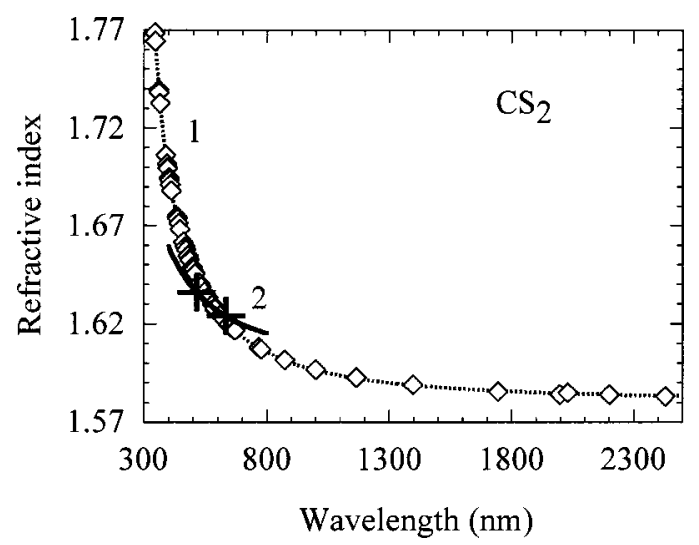

FIG. 4. Dispersion of refractive index of liquid $\mathrm{CS}_{2}$ at $20^{\circ} \mathrm{C}$. Diamonds are the experimental data from Table IV; crosses are the data measured in Ref. 1. Curve 1 (dotted line) was calculated using $n=1.580826+15238.9 / \lambda^{2}$ $+4.8578 \times 10^{8} / \lambda^{4}-8.2863 \times 10^{13} / \lambda^{6}+1.4619 \times 10^{19} / \lambda^{8} ;$ curve 2 (solid line) is the dispersion curve from Ref. 1 . version 93 (MOPAC-93) program. ${ }^{26}$ The geometry of molecules was initially set with the CSC CHEM3D PLUS program, ${ }^{27}$ then optimized with MOPAC-93. The Austin Model 1 (AM1) method was used in the MOPAC to perform computations of electronic properties of molecules in the ground state, the polarizability $\alpha$, first hyperpolarizability $\beta_{(\mathrm{SHG})}$, and second hyperpolarizability $\gamma_{(\mathrm{THG})}$, as a function of frequency, by the time-dependent coupled perturbed Hartree-Fock method. The theoretical $\alpha$ values were used to calculate refractive indices using the Lorentz-Lorenz equation. ${ }^{6}$ It appeared that the theoretical $n$ values do not agree with the experimental data. The dispersion curve was parallel to the experimental one at longer wavelengths (above $1.5 \mu \mathrm{m}$ ), however, the slope was different at shorter wavelength when the electronic resonance was approached.

From the experimental point of view it is useful to learn about the temperature derivative of refractive index $d n / d T$ for these standard liquids. The data listed in Ref. 1 are quite different from these collected in Ref. 7. For example, the gradient $d n / d T$ at $632.8 \mathrm{~nm}$ is equal to -6.328 $\times 10^{-4} \mathrm{~K}^{-1}$ in chloroform, ${ }^{1,3}$ while it is equal to -5.98 $\times 10^{-4} \mathrm{~K}^{-1}$ in the citation. ${ }^{7}$ A similar discrepancy was found in toluene, where $d n / d T=-5.273 \times 10^{-4} \mathrm{~K}^{-1}$ at $632.8 \mathrm{~nm},{ }^{1,2}-5.55 \times 10^{-4} \mathrm{~K}^{-1}$ in Ref. 7. A bigger disagreement was found for benzene between the value of $d n / d T$ $=-7.594 \times 10^{-4} \mathrm{~K}^{-1}$ at $632.8 \mathrm{~nm}$ in Refs. 1 and 3 and $-6.40 \times 10^{-4} \mathrm{~K}^{-1}$ in Ref. 7. However, the data for $\mathrm{CS}_{2}$ were found to be similar, $d n / d T=-7.91 \times 10^{-4} \mathrm{~K}^{-1}$ at $632.8 \mathrm{~nm}$ in Refs. 1 and 2 and $-7.96 \times 10^{-4} \mathrm{~K}^{-1}$ in Ref. 7 . The origin of the scatter of the values is not known. A similar divergence in the temperature gradient data was found at $514.5 \mathrm{~nm}$ in these solvents ${ }^{1,4}$ in comparison to other literature data. One needs to conclude that the physical parameters derived from the results obtained in Refs. 1-4, i.e., optical permittivity, molar refraction, polarizability, and molecular radius for these liquids, except for benzene, may need to be reconsidered.

\section{CONCLUDING REMARKS}

A critical examination and least-squares fitting of the available experimental refractive indices for four important solvents gave accurate values of coefficients of dispersion equations. The constants listed in the Tables V-VIII gave consistent $n$ values from Cauchy's equations, Eqs. (2) and (3).

The survey of the experimental results showed some scatter of the data. Nevertheless, due to a large number of data, the values of the standard deviation indicate relatively good quality of the fits. The error in the $n$ values was about $8.3 \times 10^{-4}$ in chloroform, $4.8 \times 10^{-4}$ in toluene, $6.8 \times 10^{-4}$ in benzene, and $3.2 \times 10^{-4}$ in $\mathrm{CS}_{2}$.

A substantial improvement in the precision of the derived dispersion parameters could be achieved with measurements using interferometry. The interferometric technique was used in Refs. 1-4. For unknown reasons the values of refractive index and dispersion given there do not coincide with other published data, except those for benzene. 
The dispersion curves of Cauchy's formulas were obtained in a broad wavelength range, about $0.3-2.5 \mu \mathrm{m}$ for these liquids, but toluene was investigated up to $830 \mathrm{~nm}$ only. ${ }^{13}$ More experimental studies in the near-infrared range are required for toluene and chloroform. Although these organic liquids are among the most commonly used solvents, their refractive properties in the near-infrared region are not sufficiently well known.

The theoretical values of refractive index and dispersion curves calculated with the MOPAC-93 do not overlap the experimental data. The slopes depart in a region of strong dispersion.

\section{ACKNOWLEDGMENT}

Australian Photonics CRC is acknowledged for support.

${ }^{1}$ H. El-Kashef, Opt. Mater. (Amsterdam, Neth.) 20, 81 (2002).

${ }^{2}$ H. El-Kashef, Rev. Sci. Instrum. 65, 2056 (1994).

${ }^{3}$ G. E. Hassan, H. El-Kashef, B. Y. El-Baradie, and M. El-Labban, Rev. Sci. Instrum. 66, 38 (1995).

${ }^{4}$ H. El-Kashef, Rev. Sci. Instrum. 69, 1243 (1998).

${ }^{5}$ American Institute of Physics Handbook, edited by D. E. Gray (McGrawHill, New York, 1972)

${ }^{6}$ J. R. Partington, An Advanced Tretease on Physical Chemistry. PhysicoChemical Optics, Vol. 4 (Longmans, Green and Co., London, 1967).

${ }^{7}$ D. N. Nikogosyan, Properties of Optical and Laser-Related Materials. A Handbook (Wiley, Chichester, UK, 1997).

${ }^{8}$ Landolt-Boernstein Numerical Data and Functional Relationships in Science and Technology, New Series, Group III: Condensed Matter, Vol. 38, Subvolume A: Refractive Indices of Inorganic, Organometallic, and Organometallic Liquids, and Binary Liquid Mixtures, edited by W. Martienssen, M. D. Lechner, C. Wohlfarth, and B. Wohlfarth (Springer, Berlin, 1996).

${ }^{9}$ Landolt-Boernstein Numerical Data and Functional Relationships in Science and Technology, New Series, Group III: Condensed Matter, Vol. 38, Subvolume B: Refractive Indices of Organic Liquids, edited by W. Martienssen, M. D. Lechner, C. Wohlfarth, and B. Wohlfarth (Springer, Berlin, 1996).

${ }^{10}$ Handbook of Spectroscopy, Vol. 2, edited by J. W. Robinson (CRC, Cleveland, 1974).

${ }^{11}$ R. E. Kagarise, J. Opt. Soc. Am. 50, 36 (1960).

${ }^{12}$ E. Moreels, C. de Dreef, and R. Finsy, Appl. Opt. 23, 3010 (1984).

${ }^{13}$ J. Rheims, J. Koeser, and T. Wriedt, Meas. Sci. Technol. 8, 601 (1997).

${ }^{14}$ P. N. Prasad and D. J. Williams, Introduction to Nonlinear Optical Effects in Molecules and Polymers (Wiley-Interscience, New York, 1991).

${ }^{15}$ M. T. Zhao, Y. P. Cui, M. Samoc, P. N. Prasad, M. R. Unroe, and B. A. Reinhardt, J. Chem. Phys. 95, 3991 (1991).

${ }^{16}$ M. Samoc, A. Samoc, B. Luther-Davies, and M. Woodruff, Pure Appl. Opt. 5, 681 (1996)

${ }^{17}$ M. Samoc, A. Samoc, B. Luther-Davies, Z. N. Bao, and L. P. Yu, J. Opt. Soc. Am. B 15, 817 (1998).

${ }^{18}$ A. Samoc, M. Samoc, B. Luther-Davies, H. Liebegott, R. Stockmann, and H.-H. Hoerhold, Proc. SPIE 3473, 79 (1998).

${ }^{19}$ M. S. Wong, M. Samoc, A. Samoc, B. Luther-Davies, and M. G. Humphrey, J. Mater. Chem. 8, 2005 (1998).
${ }^{20}$ M. S. Wong, Z. H. Li, M. F. Shek, M. Samoc, A. Samoc, and B. LutherDavies, Chem. Mater. 14, 2999 (2002).

${ }^{21}$ M. Samoc, A. Samoc, B. Luther-Davies, M. G. Humphrey, and M. S. Wong, Opt. Mater. (Amsterdam, Neth.) 21, 485 (2003).

${ }^{22}$ A. Samoc, M. Samoc, B. Luther-Davies, A. C. Freydank, and N. T. Lucas, J. Nonlinear Opt. Phys. Mater. 12, 235 (2003).

${ }^{23}$ R. S. Longhurst, Geometrical and Physical Optics, 3rd ed. (Longman, London, 1973).

${ }^{24}$ M. Born and E. Wolf, Principles of Optics. Electromagnetic Theory of Propagation, Interference and Diffraction of Light, 7th ed. (Cambridge University Press, Cambridge, England, 1999).

${ }^{25}$ J. E. Bertie and Z. Lan, J. Chem. Phys. 103, 10152 (1995).

${ }^{26}$ MOPAC-93, Molecular Orbital Package, version 93 (J.J.P. Stewart and Fujitsu Limited, Tokyo, 1993).

${ }^{27}$ CSC CHEM3DPLus, Molecular Modeling System, version 3.1.2 (Cambridge Scientific Computing Inc., Cambridge, MA, 1993).

${ }^{28}$ W. E. Forsythe, Smithsonian Physical Tables, 9th ed. (Smithsonian Institution, Washington, 1954), Table 551.

${ }^{29}$ CRC Handbook of Chemistry and Physics, edited by R. C. Weast (CRC, Boca Raton, FL, 1980).

${ }^{30}$ International Critical Tables of Numerical Data, Physics, Chemistry and Technology, Vol. 7, edited by E. W. Washburn (McGraw-Hill, New York, 1930).

${ }^{31}$ C. Marsden and S. Mann, Solvents Guide (Cleaver-Hume, London, 1963).

${ }^{32}$ Chemist's Handbook, Vol. 4, edited by B. P. Nikolskii (Khimiya, Leningrad, 1965).

${ }^{33}$ Chemist's Handbook, Vol. 1, edited by B. P. Nikolskii (Goskhimizdat, Leningrad, 1962).

${ }^{34}$ G. W. Kaye and T. H. Laby, Tables of Physical and Chemical Constants (Longman, London, 1986).

${ }^{35}$ A. M. James and M. P. Lord, Macmillan's Chemical and Physical Data (Macmillan, London, 1992).

${ }^{36}$ J. Timmermans, Physico-Chemical Constants of Pure Organic Compounds, Vol. 2 (Elsevier, New York, 1965).

${ }^{37}$ A. J. Gordon and R. A. Ford, The Chemist's Companion. A Handbook of Practical Data, Techniques, and References (Wiley, New York, 1972).

${ }^{38}$ A. F. Forziati, J. Res. Natl. Bur. Stand. 44, 373 (1950).

${ }^{39}$ F. Kolrausch, Praktische Physik. Band 3 (Teubner, Stuttgart, 1968).

${ }^{40}$ V. A. Rabinovitch and Z. Y. Khanin, Concise Chemical Handbook (Khimiya, Leningrad, 1977).

${ }^{41}$ Handbook of Biochemistry and Molecular Biology, Physical and Chemical Data, Vol. 1, edited by G. D. Fashman (CRC, Cleveland, 1976).

${ }^{42}$ Chemical Encyclopaedia, Vol. IV, edited by N. S. Zefirov (Bolshaya Rossiyskaya Entsiklopediya, Moscow, 1995).

${ }^{43}$ Chemical Encyclopaedic Dictionary, edited by I. L. Knunyants (Sovetskaya Entsyklopedia, Moscow, 1983).

${ }^{44}$ Handbuch der Physik, Band XXI, Licht und Materie, edited by H. Geiger and K. Scheel (Julius Springer, Berlin, 1929).

${ }^{45}$ H. Rubens, Vied. Ann. 45, 253 (1892).

${ }^{46}$ Landolt-Boernstein, Band II/8: Eigenschaften der Materie in ihren Aggregatzustaenden. Optische Konstanten, edited by K.-H. Hellwege and A. M. Hellwege (Springer, Berlin, 1962).

${ }^{47}$ K. Feussner, Z. Phys. 45, 689 (1927).

${ }^{48}$ A. Flatow, Ann. Phys. (Leipzig) 12, 85 (1903).

${ }^{49}$ F. Kolrausch, Praktische Physik. Band 2 (Teubner, Stuttgart, 1956).

${ }^{50}$ B. S. R. Rao, Proc. Indian Acad. Sci. Sect. A 3, 240 (1936). 